\title{
Von Räubern und Grabesleiden: (un)sichtbarer Schutz durch Amulette in und aus Gräbern
}

\section{Einstieg}

Krankheiten, giftige Tiere, missgünstige Mitmenschen, Eifersucht, Diebstahl, der unerfüllte Wunsch nach Nachwuchs und andere Kümmernisse des Lebens veranlassten Menschen schon vor Jahrtausenden, sich prophylaktisch zu schützen oder bestehenden Schaden abzuwehren. Ein beliebtes Mittel dafür waren Amulette mit verschiedenen Zwecken, die vorübergehend oder fortwährend am Körper getragen werden konnten, um so die Wirkung auf die Trägerin oder den Träger zu gewährleisten. Dieser Schutz, der eigentlich Lebenden (selbst Tieren) aber manchmal auch unbelebten, im Leben situierten Objekten und Orten (z. B. Läden) zukam, lässt sich anhand von archäologischen Funden und textlichen Überlieferungen auch in Gräbern ${ }^{1}$ nachweisen. Zudem existieren Amulette, die aus Materialien aus dem Umfeld von Gräbern hergestellt wurden. Im vorliegenden Artikel wollen wir dementsprechend Amulette unterscheiden, die 1) speziell für das Grab angefertigt wurden, 2) bereits zu Lebzeiten vom nun Verstorbenen genutzt wurden, und 3) aus Materialien aus dem Grabkontext bestehen - auch solche Amulette konnten freilich wiederum in die letzte Ruhestätte beigegeben werden. ${ }^{2}$

Im Folgenden soll dergestalt der Präsenz von Amuletten als apotropäischen Objekten in Gräbern und um sie herum anhand von einigen Beispielen und allgemeinen Überlegungen nachgegangen werden. Welche Besonderheiten haben speziell für das Grab angefertigte Amulette? Und welche Rolle spielt der Grabkontext für die Anfertigung und dortige Deponierung von Amuletten, die zumeist unsichtbar waren für die Augen der Lebenden? Die Beispiele konzentrieren sich vor allem auf das östliche Mittelmeergebiet mit dem griechisch-römischen Ägypten sowie islamisch

1 Zum Grab als „Kommunikationsraum“vgl. den Artikel von Augstein in diesem Band.

2 Bei in situ, also im Grab gefundenen Amuletten, besteht freilich die Schwierigkeit, dass an ihnen oft nicht mehr nachvollziehbar ist, ob sie speziell für das Grab angefertigt oder schon zu Lebzeiten getragen wurden. Auch werden Amulette in manchen Grabungsberichten einfach zu den Kleinfunden gerechnet und erst gar nicht näher beschrieben. Zudem ist, zumal bei organischen Amuletten, natürlich auch mit Verrottung zu rechnen. Daher müssen wir uns oftmals auf Textquellen und für die jüngere Geschichte ethnologische Untersuchungen verlassen.

Dieser Beitrag ist im Heidelberger Sonderforschungsbereich 933 „Materiale Textkulturen. Materialität und Präsenz des Geschriebenen in non-typographischen Gesellschaften“ entstanden. Der SFB 933 wird durch die Deutsche Forschungsgemeinschaft finanziert.

○ Open Access. (๑ 2018 Sarah Kiyanrad, Laura Willer, publiziert von De Gruyter. (œ) BY-NC-ND Dieses Werk ist lizenziert unter der Creative Commons Attribution-NonCommercial-NoDerivatives 4.0 Lizenz. https://doi.org/10.1515/9783110619928-005 
geprägte Kulturen, auch wenn ähnliche Phänomene ebenfalls an anderen Orten und $\mathrm{zu}$ anderen Zeiten nachweisbar sind.

Auch wenn die Beispiele folglich etwas beliebig erscheinen könnten - sie erklären sich in erster Linie durch unseren fachlichen Hintergrund -, weisen sie doch auf Parallelen wie Unterschiede in der Verwendung von Amuletten in der longue durée im funerären Kontext hin und sollen als kleiner Beitrag zur vergleichenden Amulettforschung verstanden werden.

\section{Weltliche und jenseitige Gefahren für den Verstorbenen}

Religionen, die ein Leben nach dem Tod annehmen, stehen vor der Aufgabe, dieses in ihr jeweiliges Glaubenssystem zu integrieren; dabei kann, wenn Erdbestattungen vorgenommen werden, das Grab einen gewissen Übergangscharakter bekommen. Dort galt es den Verstorbenen zu schützen; sei es, indem man das Grab selbst mit Amuletten ausstattete, sei es, dass dem Verstorbenen solche mitgegeben wurden. Bei dem Bedürfnis ihn und seine Umgebung zu behüten, scheint sowohl der Gedanke an jenseitige Gefahren eine entscheidende Rolle gespielt zu haben sowie auch die den Lebenden eher unangenehme Vorstellung von der Dunkelheit, Enge und Trockenheit bzw. je nach klimatischen Umständen auch Verwesung fördernder Feuchtigkeit im Grab. Amulette konnten also durchaus auch vor dem Grab selbst schützen, denn es war nicht immer ein nur positiv konnotierter, sondern, wie wir sehen werden, auch ein als gefährlich perzipierter Ort. Bevor wir zum Hauptthema kommen, sollen daher zunächst einige allgemeine Überlegungen zum Thema Grab vorangestellt werden sowie zu den möglichen Gefahren, denen der Tote sich - in der Vorstellung der Lebenden - ausgesetzt sah.

Zunächst kann festgestellt werden, dass dem leblosen Körper regelmäßig eine ganz besondere, je nach Kultur und Glaubenssystem komplexe Behandlung widerfuhr. Dazu konnten z. B. die Waschung und eine spezielle Bekleidung gehören. In manchen Kulturen, wie z. B. islamisch geprägten, sollten Tote möglichst schnell beerdigt werden, in anderen war mit der Vorbereitung des Körpers auf das Grab, beispielsweise der Mumifizierung, eine zeitaufwändige Prozedur verbunden.

In Ägypten wurden die Verstorbenen jahrtausendelang mumifiziert. ${ }^{3}$ Auch wenn diese Technik erst um 600 n. Chr. in Vergessenheit geriet, so nahmen doch insbesondere seit christlicher Zeit Bestattungen in einfachen Tüchern oder Tuniken zu, wie es

3 Die ältesten durch Menschen präparierten Mumien datieren um 3600 v. Chr.; Theis 2011, 21. 
ähnlich auch im Islam geschieht. ${ }^{4}$ Bekanntlich werden Muslime mit einem weißen Leichengewand ${ }^{5}$ am Leib und mit dem Gesicht in Richtung Mekka begraben. Ihrem Glauben gemäß verbleiben sie (zumindest leiblich) bis zum Tag des Jüngsten Gerichts im Grab (arab. qabr, hufra) und werden dann von Gott erweckt: „Am Tag, da er euch (zum Gericht) rufen wird! Da werdet ihr ihm antworten, indem ihr sein Lob anstimmt, und dabei der Meinung sein, ihr hättet nur kurze Zeit (im Grab) verweilt“. ${ }^{6}$ Erst danach wird von Gott entschieden, ob der Mensch in den Himmel oder die Hölle kommt. In der Zwischenzeit, vom Tod bis zum Jüngsten Gericht aber, nimmt der Körper des Menschen im Grab Aufenthalt. ${ }^{7}$ Im antiken Ägypten jedoch wurde der Körper durch die angesprochene Mumifizierung erhalten. Dies wurde für ein Fortleben im Jenseits zu allen Zeiten als wichtig erachtet, auch wenn sich die ägyptischen Jenseitsvorstellungen im Laufe der Jahrtausende veränderten. ${ }^{8}$

In den religiösen Texten der pharaonischen Zeit wird neben mythischen Gefahren wie Dämonen auch anderweitig drohendes Unheil thematisiert. ${ }^{9}$ In den ca. 2300 v. Chr. aufkommenden Pyramidentexten, die u. a. das Überwinden jeglicher Gefahren, die dem verstorbenen Pharao bevorstehen konnten, zum Ziel hatten, zählen dazu auch Bedrohungen wie sie bei einem physischen Aufenthalt im Grab naheliegend waren und Jahrtausende später noch den muslimischen Verstorbenen bevorstanden: Dunkelheit, Verwesung, Hunger, Durst, Schlangen und Skorpione. ${ }^{10}$ Das Totenbuch, das ab dem Neuen Reich (1550-1070 v. Chr.) die maßgebliche Literatur zum Schutz des Verstorbenen darstellte, befasst sich unter anderem mit ähnlichen Themen wie der Abwehr von Schlangen und Krokodilen, dem Bedürfnis zu atmen und zu trinken und der Sorge davor, ein zweites Mal sterben zu müssen; es bietet aber

4 Auch wenn der Mumifizierungsprozess selbst dabei Veränderungen unterworfen war; Theis 2011, 36-39; Torallas Tovar 2013, 13-16. Neben dem Nischengrab war in der Frühzeit des Islam auch das Schachtgrab verbreitet. Zum Grab im Frühislam vgl. ausführlich Grütter 1956, 168-175; zuvor auch schon Wellhausen 1897, 179f. Selbstverständlich darf dies nicht darüber hinwegtäuschen, dass im Laufe der Jahrhunderte diverse Funerärarchitekturen Gestalt annahmen; vgl. z. B. Leisten 1998; Bunce 2004; Bhalla 2009; Sörries 2015.

5 Wobei die Qualität und Gestalt desselben durchaus den sozioökonomischen Status des Verstorbenen widerspiegeln kann. Halevi 2007, 85 schreibt: „In the early Islamic period, shrouds came in a variety of materials and colors, plain or decorated with dancing figures and arabesque patterns.“

6 Sure XVII, 52; ähnlich etwa auch in Sure LXXIX, 46; vgl. auch Sure XXIII, 16; LXXX, 21-22. Die deutsche Übersetzung des Korans wird im Folgenden nach Rudi Paret zitiert.

7 Auf diese Zeit wird auch als barzah referiert; jedoch bleibt der Koran über die genaue Gestalt der Zeit zwischen Tod und Auferstehung im Ungenauen; vgl. ausführlich O`Shaughnessy 1969; Smith/ Haddad 1981; Rebstock 2002; Lange 2011; Tesei 2016.

8 Für einen knappen Überblick über die Jenseitsvorstellungen und ihre Veränderungen Mannsbart 2003.

9 Detailliert zum ägyptischen Grabschutz Theis 2014, 433-573.

10 Den verstorbenen Pharaonen drohten noch weitere Übel wie Krankheiten, in den eigenen Mumienbinden gefesselt zu sein oder das Absterben der Seele, welches Verjüngung und ewiges Leben verhindert hätte; Meurer 2002, 228-315. 
auch Amulettsprüche zur Sicherung von Grab und Gestorbenem. ${ }^{11}$ Die Angst vor dem Ersticken im Grab könnte auch in einer Gruppe hieratischer und demotischer Funerärtexte ausgedrückt sein, die den Titel Buch vom Atmen tragen. ${ }^{12}$

Im Islam geht die Zeit im Grab mit Prüfungen einher, wie zwar nicht direkt im Koran, ${ }^{13}$ dafür aber in den Hadithen und darauf aufbauend im sogenannten Islamischen Totenbuch angesprochen wird. Dabei fürchten sich die Muslime ganz besonders

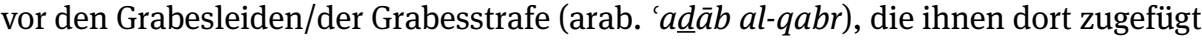
werden können. In den Hadithen ist eindeutig vermerkt, dass Muhammad diese als existent betrachtete. ${ }^{14} \mathrm{Im}$ Grab wird der Verstorbene zu seinen Taten befragt (arab. musā'ala); vor allem soll aber auch geklärt werden, ob der Verstorbene Muslim war. ${ }^{15}$ Diese Befragung wird im Glauben vieler Muslime durch zwei Grabesengel, Nakīr und Munkar, durchgeführt. ${ }^{16}$ Je nach Ergebnis der Befragung folgt dann möglicherweise eine unmittelbare Bestrafung, also die Grabesleiden. Zu ihnen gehören Hitze, Druck, Schläge und Schlangenbisse, also ebenfalls Züchtigungen, denen die physischen Gegebenheiten eines Grabes zugrunde liegen. ${ }^{17}$ Gerade Schlangen und Skorpione

11 Abwehr von Schlangen und Krokodilen: Tb 31-40; Atmen: Tb 54-59; Trinken: Tb 62-63a; ein zweites Mal sterben müssen: Tb 41-46, 175-176; Amulette: Tb 29b, 156-160, 186. Vgl. auch das Totenbucharchiv der Universität Bonn: http://totenbuch.awk.nrw.de/ (Zugriff am 29.01.2018). Es existiert auch ein islamisches Totenbuch, das aber keine Amulettsprüche beinhaltet; die genaue Verfassungszeit und der Autor bleiben im Dunkeln.

12 Der Anfang des Textes („May his/her soul live for ever, may it rejuvenate eternally.“) ähnelt stark dem üblichen Formular auf Mumientäfelchen; Vleeming 2011, 780-789. Zu den Mumientäfelchen s. u. 13 Tatsächlich schweigt der Koran über das „Leben“ im Grab; Galloway 1922, 351-354.

14 Auch im Judentum existieren entsprechende Vorstellungen, wobei durchaus ein Einfluss auf die islamische Tradition angenommen werden kann, zumal Muhammad die Grabesleiden zunächst als Lüge bzw. Strafe der Juden bezeichnete, später aber seine Meinung geändert haben soll, vgl. Lange 2011.

15 Decker 2013, 164. Decker spricht die Vermutung aus, dass die Vorstellung von den Grabesleiden sich erst im 9. Jh. ganz durchgesetzt habe; ebd. 171. Auch die auf den ältesten islamischen Grabsteinen vorhandene šahāda (vgl. Halevi 2007, 20-21) zielt darauf ab, die Religion des Verstorbenen zu bezeugen. Gefragt wird der Verstorbene nach seinem Gott, seinem Propheten und seiner Religion.

16 Lange 2011; zu anderen Anzahlen und Namen von Engeln vgl. Eklund 1941, 36f.

17 Lange 2011; zur Schilderung einiger Strafen in den Quellen exemplarisch Kinberg 1986, 293-294; Das Islamische Totenbuch 2002, 93. Möglicherweise werden Tote im Grab auch für die Totenbeweinung durch ihre Angehörigen bestraft; vgl. dazu ausführlich, auch unter Einbezug ähnlicher negativer Konnotationen der Totenbeweinung in anderen Kulturen, Meier 1973. Siehe auch Sörries 2015, 24-25. In Marokko dürfen die Tränen der Hinterbliebenen nicht das Gesicht des Toten berühren, sonst hat dieser Grabesleiden zu erwarten, vgl. Westermarck 1926, II, 435-436. Das Islamische Totenbuch deutet an, dass Trauernde ob ihrer Trauer einmal selbst Grabesleiden zu erwarten hätten (Das Islamische Totenbuch 2002, 81), spezifiziert an anderer Stelle aber, Tränen seien erlaubt, was nicht gelte für „den Klagelaut und den [Laut] des Trauergesanges; ferner das Zerkratzen des Gesichts und das Zerschlagen des Busens“ (ebd., 83). Ein von Jürgen Wasim Frembgen dokumentierter, in Pakistan erzählter Bericht beinhaltet, dass sich in einem frisch ausgehobenen Grab für einen verstorbenen Mann Skorpione befanden, woraufhin der Mulla veranlasste, ein neues auszuheben. In diesem bemerkte man dann zwei Schlangen (vgl. Jürgen Wasim Frembgen 2004, 192-193), beide Tiere symbolisieren 
spielen bei der Bestrafung der Sünder in der Hölle eine zentrale Rolle. ${ }^{18}$ Um den Durst des Toten zu stillen, werden Gräber regelmäßig gewässert.

Das Bildnis von Hunger und Durst findet sich auch in der griechischen Mythologie. Dort muss Tantalos für seine Freveltaten für immer im Tartaros büßen, wo er Hunger und Durst litt, obwohl er in Wasser stand und sich ein Obstbaum über ihn neigte. In den im Folgenden noch $\mathrm{zu}$ thematisierenden orphischen Goldtäfelchen erscheint ebenfalls das Motiv, dass der Verstorbene durstig ist. ${ }^{19}$

Während Hunger, Durst, Atemnot usw. Gefahren für den Verstorbenen darstellten, waren die Schlangensprüche der Pyramidentexte bipolar ausgelegt. ${ }^{20}$ Einige richten sich gegen (ins Grab eindringende) Schlangen als Feinde, andere ließen auf die Verteidigung der Grabanlage durch Schlangen gegen anderweitig eindringende Feinde hoffen. Durch die Unsichtbarkeit der innerhalb der Pyramiden angebrachten Sprüche wird klar, dass sie durch ihre Präsenz wirkten. ${ }^{21}$

Das Grab konnte die Menschen schon zu Lebzeiten adressieren und ihn zur Frömmigkeit ermahnen; gemäß einer Überlieferung, die im Islamischen Totenbuch wiedergegeben wird, ruft das Grab den Menschen täglich dreimal zu: „Ich bin das Haus der Einsamkeit. Ich bin das Haus der Finsternis. Ich bin das Haus der Würmer. Was hast du nun aus dieser Menschenwelt für diesen wüsten Ort dir vorbereitet?“22 Damit wird der Übergangsort zu einem potenziell bedrohlichen Ort - vor dem bzw. den mit ihm einhergehenden Leiden man sich schützen wollte. Es wurde angenommen, dass Nichtmuslime die genannten Leiden im Grab grundsätzlich zu spüren bekämen. ${ }^{23}$ Aber auch Muslime sahen sich von ihnen bedroht. So liest sich beispielsweise, dass üble Nachrede oder aber die Nichtdurchführung der rituellen Waschung vor dem Gebet sowie Verunreinigungen (durch Urin) Gründe für spätere Grabesleiden sein können. ${ }^{24}$ Diese Grabesleiden sind einer der wichtigsten Aspekte, für die Grabamu-

das Böse, denn der Verstorbene genügte den moralischen Anforderungen seiner Zeit nicht - möglicherweise werden aber auch schon die bevorstehenden Grabesleiden durch diese Tiere angedeutet? Eine ähnliche Erzählung findet sich schon in früherer Literatur, vgl. Eklund 1941, 32f.

18 Solche Szenen wurden auch in Omenbüchern abgebildet; für ein safawidisches Beispiel vgl. Gruber 2016, 318, Fig. 13.7. Freilich drängen sich hier Parallelen zu vorislamischen, speziell zoroastrischen Vorstellungen auf, wie sie sich auch noch im Ardā Wìrāz-nāmag finden.

19 Bernabé/Jiménez San Cristóbal 2008, $207 f$.

$20 \mathrm{Zu}$ weiteren Beispielen bipolar wirkender Schutzmechanismen rund um Gräber s. u.

21 Theis 2014, $464 \mathrm{u}$. 477f.

22 Das Islamische Totenbuch 2002, 73.

23 In den Hadithen sind dabei speziell Juden angesprochen, vgl. Eklund 1941, 2f.

24 Exemplarisch in folgenden schiitischen Quellen: al- 'Ảmilī 1412, I, 94, 100; idem 1409, I, 340, VII, 392, X, 35, XXI, 345; Mağlisī 1423, LXXVII, 167, 210; C, 286. Entsprechende Hinweise tauchen u. a. bereits bei Ibn Sa'd auf und wurden folglich über Jahrhunderte tradiert; vgl. Eklund 1941, Decker 2013, 168. 
lette angefertigt wurden; ${ }^{25}$ dies obwohl im Islam grundsätzlich keine Grabbeigaben vorgesehen sind.

Sogar schon vor ihrer Bestattung benötigten Verstorbene Schutz, nicht nur vor den jenseitigen Übeln und den Gefahren im Grab, sondern auch vor der Zweckentfremdung und Nachlässigkeit ihrer Mitmenschen. Der als „Verwünschung der Artemisia“ bekannte griechische Papyrus UPZ I 1 aus dem 4. Jh. v. Chr., in dem eben jene Artemisia dem Vater ihrer Tochter einen Tod ohne folgende Bestattung wünscht, weil er dem Kind das Begräbnis verwehrt hat, könnte ein Hinweis darauf sein, dass es eventuell möglich war, die Mumie eines Verwandten zu verpfänden. ${ }^{26}$ Eine ebenfalls griechische Anzeige, ${ }^{27}$ die im Jahr 127/6 v. Chr. wegen Einbruchs in ein Gemeinschaftsgrab aufgegeben wurde, enthält nicht nur den Tatbestand, dass Mumien ausgewickelt wurden, sondern auch, dass in Folge die noch unbestatteten Leichname von Schakalen gefressen wurden, weil die Diebe die Tür hinter sich offen ließen. Für beide menschliche Sorglosigkeiten blieb genug Zeit, da der Mumifizierungsprozess in der Regel etwa 70 Tage in Anspruch nahm. ${ }^{28}$

Dass die Sicherung nicht nur des Toten selbst, sondern auch seines Begräbnisplatzes in Ägypten seit vordynastischer Zeit relevant war, zeigen all die Mechanismen, die in den Grabanlagen installiert wurden, um Grabräuber fernzuhalten. ${ }^{29}$ Dass Grabräuber auch in muslimischen Gräbern ihr Unwesen trieben, zeugt davon, dass dort durchaus wertvolle Grabbeigaben zu finden waren. ${ }^{30}$ Jedoch fehlen bisher Hinweise auf aufwendige Abwehrkonstruktionen wie im altägyptischen Kontext. Vom Ende des 2. Jt. v. Chr. sind uns von dort sogar die Verhörprotokolle von Grabräuberprozessen erhalten, aus denen ersichtlich wird, dass es sich um Banden von Wiederholungstätern handelte. ${ }^{31}$ Ihr Beweggrund war nicht unbedingt Gier, sondern konnte auch das blanke Überleben sein, nämlich als die Zahlungen an die Arbeiter im Tal der Könige

25 Freilich gilt dies nicht für alle Muslime; so glaubten beispielsweise Hāariğiten und Mu'taziliten nicht an die Grabesstrafe, vgl. Decker 2013, 169-170.

26 Kreuzsaler 2013, 50-53.

27 UPZ II 187.

28 Quaegebeur 1978, 238 [= P. Batav.]. Sogar bei dem Mumifizierungsprozess selbst wurden ab der ägyptischen Spätzeit den Leichen teilweise die Knochen gebrochen oder Ähnliches angetan, um den Körper in den ihm zugedachten Sarg zu bekommen, vgl. Theis 2011.

29 Vgl. dazu Clark 2016.

30 Schöller 2004, 206 Anm. 271 beschreibt anhand belegter historischer Beispiele, dass sie u. a. auf Münzen und Stoffe zu hoffen hatten; vielleicht sollten große, das Grab bedeckende Steinplatten auch dazu dienen, ihnen die Arbeit zu erschweren.

31 Die betroffenen Gräber liegen im Tal der Königinnen. Die Gräber im Tal der Könige wurden dagegen von Amts wegen geräumt, um einerseits die Mumien zu bewahren, andererseits um Ausstattung und Beigaben als Schatzkammer zu nutzen; Jansen-Winkeln 1995. Zu den Grabräuberpapyri vgl. Peet 1930 und Capart/Gardiner/van de Walle 1936. 
ausblieben. ${ }^{32}$ Da ein einzelner Raub bis zu mehrere Jahresgehälter einbringen konnte, lohnte sich dieses verbrecherische Vorgehen. ${ }^{33}$

Doch Grabschändung schloss nicht nur Grabraub ein, also dass wertvolle Gegenstände wie die Kleidung des Bestatteten aus der Begräbnisstätte entwendet wurden, sondern auch die zusätzliche Beerdigung eines Fremden in einem bereits belegten Grab oder der Diebstahl bzw. Veränderungen des Grabmonuments. ${ }^{34}$ Dazu gehörte auch der Tatbestand, einen zweiten Leichnam in dasselbe Grab zu legen, was im griechischen Kleinasien juristisch mit einer Geldstrafe geahndet wurde. ${ }^{35}$

\section{Für das Grab angefertigte Amulette}

Neben dem Grab selbst sollte aber mindestens genauso häufig speziell der Leichnam des Verstorbenen durch Amulette beschützt werden. Von den ungefähr 200 griechischsprachigen Papyrusamuletten aus Ägypten ist nur bei knapp zehn der Fundkontext gesichert. ${ }^{36}$ Von diesen wiederum stammt nur ein einziges aus einem Grab - in diesem Fall sogar mit der einmaligen Intention, dem Toten Schutz zu bieten. Das Unikat stammt aus dem 2. oder 3. Jh. n. Chr. und lässt sich sogar als Mumienamulett bezeichnen. Denn seine Aufschrift spricht nach etlichen Anrufungen eindeutig davon, die Mumie des Gestorbenen vor Grabräubern und Leichenschändern zu beschützen: „Ihr, schöne und preiswürdige Götter, bewahret Mumie und Leib und gesamtes Grab des Phtheious des Jüngeren bzw. Saionëis, Sohnes der Sentaësis [...]“. ${ }^{37}$ Hier wurde also vermutlich von den Angehörigen ein Amulett speziell für den Toten angefertigt; das heißt, es wurde im Gegensatz zu allen anderen Papyrusamuletten nicht schon zu Lebzeiten am Leib getragen. ${ }^{38}$

Ebenfalls speziell für die Verstorbenen beschriftet wurden besonders im 4. und 3. Jh. v. Chr. in Griechenland und Italien kleine Goldblättchen mit schutzbringenden

32 Peet 1930, 12f; Höveler-Müller 2007, 29, 53f., 61.

33 Höveler-Müller 2007, 38, 51, 54, 63f., 72.

34 Insbesondere ärmere Bevölkerungsschichten, die sich kein eigenes Grab(monument) leisten konnten, mussten darauf zurückgreifen, vgl. Strubbe 1997, XIII.

35 Strubbe 1991, 33f.

36 Ausführlich zu griechischen Papyrusamuletten Willer 2015.

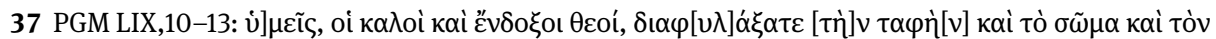

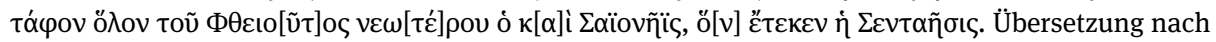
Henrichs, in: Preisendanz 1974, 187 [= PGM Bd. 2]. Saionëis ist der Aliasname des Verstorbenen.

38 Dass der apotropäische Papyrus wie bleierne Verfluchungen (defixiones) mit einem Nagel durchbohrt wurde, wie der Ersteditor Preisendanz vermutet, ist unwahrscheinlich; vgl. Preisendanz 1932, 19. Die regelmäßigen Löcher im Papyrus müssen auf eine andere Ursache in den letzten 2000 Jahren zurückgehen. 
Texten in Griechisch. ${ }^{39}$ Diese sogenannten orphischen Goldtäfelchen wurden jedoch im Gegensatz zu Textamuletten, die man zu Lebzeiten zusammengefaltet oder -gerollt in einem Anhänger um den Hals trug, offen auf dem Brustkorb des Toten platziert; gefaltet wurden sie ihm in Handfläche oder Mund gelegt. ${ }^{40}$ Im letzteren Fall werden dem Toten nicht nur die richtigen Worte wortwörtlich in den Mund gelegt, sondern das Täfelchen erinnert auch an die Münze, die man den Toten in den Mund legte, damit sie gemäß der griechischen Mythologie den Fährmann in den Hades, Charon, bezahlen konnten. ${ }^{41}$ Die Texte der orphischen Goldtäfelchen drücken nicht nur die Hoffnung auf ein glückliches Nachleben aus, sondern geben insbesondere Anweisungen, wie dies zu erreichen sei, wie die Seele an den unterschiedlichen Stationen auf ihrer Reise ins Jenseits die bevorstehenden Prüfungen meistert. ${ }^{42}$ Insofern waren die beschriebenen Artefakte explizit für ein Leben nach dem Tod gedacht. ${ }^{43}$ Denn die Anhänger dieser Glaubensströmung waren überzeugt, dass ihnen im Jenseits ein besonderer Ort und Zustand zukam. ${ }^{44}$ Das gewählte Material, Gold, sollte schädigende Einflüsse abwehren und die Dauerhaftigkeit des nächsten Lebens symbolisieren. ${ }^{45}$

Die Hoffnung auf ein Leben nach dem Tod drücken in Ägypten etliche der Mumienetiketten aus. Seit ptolemäischer Zeit wurden die Mumien bis ins 4. Jh. n. Chr. hinein mit einem Etikett versehen, auf dem ihr Name vermerkt war, sodass sie bereits vor der Mumifizierung sicher zu identifizieren waren und danach das ihnen persönlich zustehende Opfer erhielten. ${ }^{46}$ Die griechischen Täfelchen blieben so einfach gehalten, mit Ausnahme von Kondolenzbekundungen wie sie auch auf Grabsteinen vorkamen. ${ }^{47}$ Das „Andauern des Namens“ war ein zentrales Thema in der ägyptischen Funerärliteratur und die Griechen im Mutterland waren besorgt darüber, dass ihr Name vergessen werden könnte. ${ }^{48}$ Dadurch kam den Tafeln auch eine kommemorative Funktion

39 Das jüngste Exemplar datiert auf die Jahre um 260 n. Chr.; Bernabé/Jiménez San Cristóbal 2008, $2-4$.

40 Bernabé/Jiménez San Cristóbal 2008, 4.

41 Bernabé/Jiménez San Cristóbal 2008, 4, 230. Zu Münzen in Gräbern s. u.

42 Bernabé/Jiménez San Cristóbal 2008, 5f., 172-174.

43 Etliche gestehen den orphischen Goldtäfelchen auch eine Amulettfunktion schon zu Lebzeiten zu (Auflistung bei Faraone 2010, 155 Anm. 26). Das vielzitierte Täfelchen aus Petelia ist dafür kein Beleg, da es nicht gesichert in einer Amulettkapsel entdeckt wurde, sondern möglicherweise nur in ihrer Nähe, vgl. Marshall 1911, 380f. Ausführlicher zu dieser Tafel Willer 2015.

44 Bernabé/Jiménez San Cristóbal 2008, 2, 174-178.

45 Bernabé/Jiménez San Cristóbal 2008, 2.

46 Zur Datierung: Vleeming 2011, 775f.; Quaegebeur 1978, 241 [= P. Batav.]. Zur Identifikation: Quaegebeur 1978, 235 [= P. Batav.]; Arlt 2011, 225-227. Ausführliche Bibliographie zu Mumientäfelchen unter http://deathonthenile.upf.edu/bibliography/ (Zugriff am 29.01.2018).

47 Quaegebeur 1978, 237, 251 [= P. Batav.].

48 Strubbe 1991, 40. Arlt 2011, 111. Dieser Gedanke ist mancherorts auch muslimischen Gläubigen nicht fremd und beunruhigt den frisch Verstorbenen, sodass er sich, wenngleich nicht hörbar für die Lebenden, gemäß dem Islamischen Totenbuch wie folgt ausdrückt: „Bei Gott, meine Brüder, ich weiß sehr wohl, dass der Tote vergessen wird, aber ich bitte euch, dass ihr euch in dieser Stunde nicht eher von hier abwendet, bis dass ihr mich unter die Erde gebracht habt.“ Und er bittet: „Vergesst mich [...] 
zu, auch wenn sie in den unterirdischen Grabanlagen nicht für die Öffentlichkeit, sondern nur für die zuständigen Priester zugänglich und damit sichtbar waren - im Gegensatz zu oberirdischen Grabsteinen. ${ }^{49}$ Auf den demotischen Tafeln wurde in der Regel zusätzlich eine religiöse Formel angefügt, die zumeist mit „Ihre/seine Seele möge leben (für immer und ewig)“ begann..$^{50}$ Wenn den Toten damit auch kein expliziter Schutz mitgegeben wurde, so doch immerhin Wünsche für das Jenseits.

Als Ausdruck von Jenseitshoffnung lässt sich auch ein christliches Leichentuch aus dem 5.-6. Jh. bezeichnen, das eine Anspielung auf die Auferstehung enthält, die einem Zitat aus dem apokryphen Thomasevangelium ähnelt. ${ }^{51}$ Luijendijk vergleicht die Aufschrift mit Amuletten, die möglichst nah am Körper getragen werden sollen, wie auch Passagen aus dem ägyptischen Totenbuch in griechisch-römischer Zeit teilweise direkt auf die Mumienbinden geschrieben wurden. ${ }^{52}$ Nach demselben Prinzip wird auch noch auf einem Leichentuch aus arabischer Zeit der Herr gebeten, dem Verstorbenen Ruhe zu gönnen. ${ }^{53}$ Auch wenn das Tuch um einen Christen gewickelt war, so ist das mit Tinte aufgetragene Gebet schon zweisprachig koptisch und arabisch verfasst. Bei diesen Leichentüchern und ihren Beschriftungen reicht also nicht ihre simple Präsenz im Grab aus, sondern es geht dezidiert um eine genaue Lokalisation möglichst nahe am Körper des Eingewickelten.

Wie wir weiter unten sehen werden, wurde auch in islamischer Zeit die Möglichkeit, das Leichentuch zu beschriften, oftmals realisiert. Bei denjenigen islamischen Amuletten, die speziell für das Grab angefertigt bzw. dem Verstorbenen beigegeben wurden, ohne dass sie schon zu Lebzeiten in seinem Besitz gewesen sein mussten, scheint die religiöse Symbolik eine bedeutende Rolle gespielt zu haben: Das entsprechende Objekt sollte eben auch kennzeichnen, dass die Trägerin oder der Träger sich zum Islam bekannte. So beobachtete Bess Allen Donaldson zu Beginn des 20. Jh. bei der Leichenwaschung ${ }^{54}$ in Iran:

nicht, sondern gedenkt meiner durch große Freigiebigkeit. [...] Vergesst mich nicht in euren Gebeten!“ (Das Islamische Totenbuch 2002, 78).

49 Arlt 2011, 225-228.

50 Arlt 2011, 110.

51 Luijendijk 2011. Dort auch Hinweise auf einzelne Vergleichsstücke.

52 Luijendijk 2011, $405 f$.

53 Delattre/Vanthieghem 2015. Auch wenn die auf christlichen Leichentüchern aus Ägypten aufgestickten Gebete normalerweise keinen Bezug zu Tod oder Auferstehung aufweisen; Delattre/Vanthieghem 2015, 196 insb. Anm. 8. Bei Stauffer sind zahlreiche spätantike Textilien aus dem östlichen Mittelmeerraum beschrieben und abgebildet, von denen zwar nur eine aus dem 10./11. Jh. (Stauffer 1996, 70, Kat. 51) eine (koptische) Inschrift besitzt, die aber insgesamt deutlich von Kontinuitäten auch in der Totenkleidung über Jahrhunderte hinweg bis weit hinein in die islamische Zeit zeugen (vgl. ebd., 7-8).

54 Westermarck 1926, II, 443 berichtet, dass in Marokko Hinterbliebene mit den entsprechenden finanziellen Mitteln gerne Leichenwäscher engagierten, die baraka (s. u.) besaßen; vermutlich, damit der Segen auf den Verstorbenen ausstrahlte. 
In many cases an agate seal, with the name of the ,Five' cut into it, is put under the tongue; or a coin bearing the same names, or a rosary of unbaked clay from Kerbala, is placed in the hand. A ring with the name of the ,Fourteen' scratched or cut into it is put on a finger of the right hand, and a long prayer, which is called the ahd námah is forced into his hand to show that the deceased is one of Muhammad's people..$^{55}$

Tatsächlich wurde in Udegram, Pakistan, auf einem muslimischen Friedhof das Skelett eines Mannes gefunden (aus der Zeit zwischen dem Ende des 11. und dem Ende des 13. Jh.), der einen Rosenkranz aus Bergkristall in der Hand hielt und eine Amuletthülle aus Bronze um den Hals trug. ${ }^{56}$ Der möglicherweise einmal vorhandene Inhalt der Hülle, d. h. wohl ein Papier- oder Tierhautamulett, war nicht erhalten. $\mathrm{Zu}$ Beginn des 20. Jh. beobachtete Westermarck in Marokko, dass dem Toten die verschriftlichten Antworten auf die Fragen der gefürchteten Todesengel gelegentlich unter den Kopf gelegt wurden. ${ }^{57}$

Neben genuin auf die Religion des Trägers verweisenden Artefakten waren auch Reliquien im weiteren Sinne oder Objekte, die verehrten religiösen Persönlichkeiten gehört haben, geeignete Grabamulette. ${ }^{58}$ So sollen sich Zeitgenossen des Propheten Muhammad gewünscht haben, dass ihnen ins Grab Fingernägel und Haare von diesem beigegeben werden..$^{59}$ Falls die oder der Tote schon zu Lebzeiten entsprechende Objekte besaß, wurden sie entsprechend beigegeben; aber auch wenn nicht, stellten z. B. im schiitischen Kontext Täfelchen, die aus Lehm vom Grab des Ḥusain in Kerbala oder dessen Umfeld bestanden, ein geeignetes Grabamulett dar. ${ }^{60} \mathrm{Nicht}$ alle Amulette mussten unmittelbar ins Grab gelegt werden; wie ein Beispiel aus Tansania aus dem 19. Jh. zeigt, wurden einige im Umfeld des Grabs, also oberhalb der Erde angebracht. ${ }^{61}$ Zwar liegt hier nahe, anzunehmen, dass nicht das Grab mit diesen geschützt werden sollte, sondern im Gegenteil, Besucher intendierten von der Heiligkeit des Grabes zu profitieren und ihre Wünsche in dessen Nähe fixierten, jedoch sollte auch die Möglichkeit, dass solche für alle sichtbaren Wunschbänder (Fetzenopfer), in Kombination mit Gebeten für den Verblichenen, auf das Grab zurückwirken sollten, nicht ausgeschlossen werden.

Es bestand auch die Option, Gräber auf andere Weise für die Lebenden sichtbar zu schützen. Die auf Amuletten beliebten Namen der Siebenschläfer sind u. a. an der

55 Donaldson 1938, 72. Für erhaltene Siegelsteine mit den Namen „der 5“ (Muhammad, 'Alī, Fāțima, Ḥasan und Ḥusain) und „der Vierzehn“ (Muḥammad, Fāțima und die zwölf schiitischen Imame) vgl. z. B. Porter 2011, $151 \mathrm{ff}$.

56 Bagnera 2011, 233.

57 Westermarck 1926, II, 465.

$58 \mathrm{Zu}$ Reliquien als Amulette s. u.

59 Grütter 1956, 180.

60 Donaldson 1938, 72.

61 Beschreibung von Kirk, zitiert nach Becker 2009, 419. Möglicherweise handelt es sich allerdings auch um spätere Opfergaben, s. u. 
Wand eines koptischen Grabes in Nubien, das dem 8. Jh n. Chr. zugerechnet wird, belegt. $^{62}$ Muslimische Heiligengräber wurden gelegentlich mit den Abbildungen von Schlangen und Palmbäumen (als Lebenssymbole), Händen (gegen den Bösen Blick) und Hufeisen geschützt. ${ }^{63}$ Auch Vorstellungen vom Paradies (und damit die Hoffnung, der Verstorbene möge in es eingehen) können ikonographisch evoziert werden. ${ }^{64}$ Zudem fehlen in vielen, gerade royalen, Grabkomplexen Koranzitate nicht; in jenem des Großmoguls Akbar (reg. 1556-1605) in Agra sind sogar die 99 islamischen Gottesnamen (al-asmā' al-husnā) in Marmor inskribiert. ${ }^{65}$ Und die Inschriften zahlreicher Grabsteine (datierend von 850-1580) auf dem Friedhof von Kairouan beginnen mit einem Zitat aus Sure CXII, ${ }^{66}$ die als besonders segensreich gilt. Auch die Bildprogramme christlicher Sarkophage und Katakomben, wie sie Dresken-Weiland detailliert für die Stadt Rom untersucht hat, vermitteln in verschiedenen Ausformungen die Hoffnungen auf ein jenseitiges Leben. ${ }^{67}$

Um sich im islamischen Kontext speziell vor den Grabesleiden zu schützen, konnten bereits zu Lebzeiten Vorkehrungen getroffen werden. Bestimmten Koranversen wurde die Kraft zugeschrieben, vor den Grabesleiden zu schützen. Zu diesen gehört Sure LXVII, al-Mulk: In dieser findet sich ein direkter Bezug zum Tod. So heißt es in Vers 2 „(Er) der den Tod und das Leben geschaffen hat, um euch (Menschen) auf die Probe zu stellen (und zu sehen) wer von euch am besten handelt. Er ist der, der mächtig ist und bereit zu vergeben“ und in Vers 6 ,Und diejenigen, die an ihren Herrn nicht glauben, haben (dereinst) die Strafe der Hölle zu erwarten ein schlimmes Ende!“ In Vers 10 liest sich „Und sie sagen (weiter) Wenn wir (seinerzeit auf die Warnung) gehört hätten oder verständig gewesen wären, würden wir uns (jetzt) nicht unter den Insassen des Höllenbrandes befinden. "Gleichzeitig wird in der Sure Gottes Allmacht angesprochen; z. B. in Vers 15: „Er ist es, der euch die Erde untertan (w. gefügig) gemacht hat. Geht auf ihrem Rücken (w. auf ihren Schultern) umher und eßt von dem, was er (euch) beschert hat! Und zu ihm führt (w. ist) (dereinst) die Auferweckung (von den Toten)“.

Muhammad selbst soll noch zu Lebzeiten Gott täglich im Gebet darum ersucht haben, die Grabesleiden nicht erfahren zu müssen. Der bislang älteste entdeckte islamische Grabstein, auf dem ein Koranzitat enthalten ist, birgt ein Zitat aus Vers 1 der

62 Seligmann 1914, 379. Allerdings wurde dieses später in eine Kirche umgewandelt, sodass nicht ganz klar ist, wann die Inschriften angebracht wurden, vgl. ebd., 382-383.

63 Kriss/Kriss-Heinrich 1960, 23; Schienerl 1980, Tafel 2d.

64 Leisten 1998, 79-83.

65 Bhalla 2009, 108. Zu Inschriften in muslimischen Mausoleen (9.-12. Jh.) vgl. Leisten 1998, 83-96. 66 Zahlreiche Beispiele finden sich bei Roy/Poinssot 1950 (u. a. S. 104, 110, 113) und Sörries 2015, 36-37; siehe auch Rahim 2010, der die Inschriften einiger Grabsteine untersucht, die zwischen das 9. und 14. Jh. datieren. Auf ihnen sind u. a. Verse aus den Suren III und IX belegt. Zu arabischen Inschriften, die in literarischen Quellen (7.-18. Jh.) belegt sind, Schöller 2004, 315-573.

67 Dresken-Weiland 2010. 
Sure $a l-M u l k .{ }^{68}$ Im Laufe des 8. Jh. scheint diese - neben anderen, wie al-Baqara - von Hinterbliebenen an den Gräbern gebetet worden zu sein, und das laute Rezitieren von Grabinschriften (mit Koranzitaten bzw. Gebeten) konnte die Grabesleiden des Dahingeschiedenen mildern. ${ }^{69}$ Noch in weit später verfassten theologischen Schriften findet sich dann der Verweis darauf, dass die Sure al-Mulk gegen die Grabesleiden schütze. ${ }^{70}$ Aber auch der für die Muslime wichtige Freitag spielt bei der Vermeidung der Grabesleiden eine Rolle: Wer in der Nacht auf einen Freitag oder an einem Freitag stirbt, muss keine Grabesleiden über sich ergehen lassen; Gleiches gilt für diejenigen, die in der Nacht zum Freitag regelmäßig die Sure al-Fātiḥa während des Ritualgebets rezitieren, ${ }^{71}$ und auch für Märtyrer. Hinterbliebene konnten durch Almosengaben, Opferungen und die Errichtung religiöser Stiftungen im Namen des Verblichenen dessen Grabesleiden mildern. ${ }^{72}$ In der islamischen Frühzeit wurden zudem Palmzweige auf manche Gräber gesteckt, welche die Grabesleiden entschärfen sollten. ${ }^{73}$ Hier bricht sich die bereits erwähnte Vorstellung von der Trockenheit im Grabe Bahn. Der Durst scheint ein dominanter Aspekt der Grabesleiden zu sein; mit dem Saft der Palmzweige wird er gestillt.

Konkrete Hinweise auf Amulette für das Grab oder speziell gegen Grabesleiden finden sich im Koran und den Hadithen, die Amuletten bis auf einige Ausnahmen eher kritisch gegenüberstehen, nicht. Solche sind aber u. a. sogenannten Magiebüchern zu entnehmen, zu deren prominentesten Aḥmad ibn 'Alī al-Būnīs (st. 1225) Šams al-ma'ārif al-kubrā gehört. Dort behandelt der Autor die Grabesleiden unter anderem im Kontext von Gottes 99 schönen Namen und dem großen Gottesnamen (al-ism al-a'zam). Zu Letzterem bemerkt al-Būnī: „Schreibst du ihn auf und gibst ihn dem Verstorbenem ins Grab bei, so ist er von den Grabesleiden befreit“. ${ }^{74}$ Während hier also ein ,klassisches' Amulett angesprochen ist, das wohl auf Papier, Metall oder Tierhaut geschrieben und dem Toten beigegeben werden konnte, so referiert eine

68 Der Grabstein gehört zum Grab der im Jahre 721 verstorbenen Fāṭima bint Ḥasan und wurde auf dem Friedhof in Assuan gefunden; vgl. Halevi 2007, 22-23.

69 Halevi 2007, 29, 31.

70 al-'Āmilī 1409, VI, 234.

71 Mağlisī 1423, LXXXVI, 271-272, 276, 277, 279, 325, 327; LXXXVII, 323.

72 Eklund 1941, 47.

73 Grütter 1956, 174-175. S. a. Halevi 2007, 228; Wellhausen 1897, 180 (er spricht von „Zweigen“). Laut Westermarck 1926, II, 458 wurden seinerzeit in Marokko Myrtenzweige und Palmblätter mancherorts auch ins Grab gelegt. Kriss und Kriss-Heinrich berichten, dass Gläubige bei der Besichtigung von Heiligengräbern gelegentlich Palmzweige darbringen, ,von denen man dann auch wieder Teile mit sich nimmt, wenn sie durch längeren Aufenthalt in der Grabkapelle den Charakter eines Schutzmittels erlangt haben“ (Kriss/Kriss-Heinrich 1960, 61).

74 al-Būnī 1322, 119. 
andere Stelle bei demselben Autor auf ein ungewöhnlicheres Beschreibmaterial. Dort geht es um den berühmten Thronvers (āyat al-kursī) (Sure II, 255):

Gott (ist einer allein). Es gibt keinen Gott außer ihm. (Er ist) der Lebendige und Beständige. Ihn überkommt weder Ermüdung noch Schlaf. Ihm gehört (alles) was im Himmel und auf der Erde ist. Wer (von den himmlischen Wesen) könnte außer mit seiner Erlaubnis (am jüngsten Tag) bei ihm Fürsprache einlegen? Er weiß, was vor und was hinter ihnen liegt. Sie aber wissen nichts davon außer was er will. Sein Thron reicht weit über Himmel und Erde. Und es fällt ihm nicht schwer, sie (vor Schaden) zu bewahren. Er ist der Erhabene und Gewaltige.

$\mathrm{Zu}$ diesem äußert sich al-Būnī wie folgt:

Schreibst du ihn an drei Stellen auf das Leichentuch (kafan) des Verstorbenen, d. h. auf den Kopf, die Körpermitte und sein Bein, dann wird er im Grab nicht leiden. Und zur Zeit der Befragung werden die Engel freundlich mit ihm sein, denn er [= der Thronvers] ist der größte Vers des Koran $[. ..] .^{75}$

Noch heute wird z. B. in Iran oftmals der Thronvers (zumeist in Kombination mit dem Gebet Ğaušan-i kabīr) auf das Leichentuch geschrieben (auch in Textilien eingewebte Verse sind bekannt); ${ }^{76}$ zudem kann beim Gebet, das über dem Verstorbenen gesprochen wird, nach jedem Abschnitt ein Knoten in einen Faden gemacht werden; dieser Faden wird dem Verstorbenen ins Grab beigegeben. Auch der Brauch, das Leichentuch bzw. das letzte Kleid vielerorts aus einer ungeraden Anzahl an Stoffteilen zu fertigen, mag apotropäischen Zwecken geschuldet sein. ${ }^{77}$ Grabinschriften, die darum bitten, die Grabesleiden des Verstorbenen zu mildern, waren ebenfalls weitverbreitet. $^{78}$

Eine weitere Möglichkeit, die gemäß einigen (zwölfer-)schiitischen Quellen zum selben Zweck realisiert werden konnte, war die Gottesnamen inklusive des größten Gottesnamens mit Kampfer oder Moschus in eine Schale zu schreiben, die Schrift dann mit Wasser auszuwaschen und das Leichentuch des Verstorbenen mit diesem zu tränken. Dann würde Gott, so die Hoffnung, tausend Lichter in das Grab schicken, dieses also erhellen, und den Verstorbenen vor der Befragung durch Nakīr und Munkar sowie den Grabesleiden schützen; auch würden ihn 7000 Engel besuchen und ihm den Weg zum Himmel öffnen. Der Leser wird zudem instruiert, das genannte Gebet - wie bei al-Būnī - auf das Leichentuch zu schreiben. ${ }^{79}$ Diese Praktik ist, wie

75 al-Būnī 1322, 286.

76 Vgl. Halevi 2007, 88.

77 Vgl. Westermarck 1926, II, 527.

78 Sörries 2015, 36 schreibt: „In Formulierungen wie das Grab weit machen, die Dunkelheit erhellen oder die Erde leicht werden lassen spiegeln sich schließlich die volkstümlichen Vorstellungen von den Grabstrafen [...]“".

79 Mağlisī 1412, 232-234; idem 1423, LXXVIII, 331, 332; XCI, 383, 400. 
schon erwähnt, mancherorts noch in jüngster Zeit zu beobachten, wobei allerdings auch argumentiert wird, dass die Koranverse schlicht bezeugen sollen, dass der Tote ein Muslim ist. ${ }^{80}$ Ein sehr spezielles Grabamulett wurde auf einem mamlukischen Friedhof gefunden: ein Straußenei, das mit Bitten an Gott beschriftet war, dem reisenden Sünder zu vergeben: „The humble sinner wrote this: he is in great need of the mercy of Allah“. ${ }^{81}$ Dabei scheint das Ei symbolisch einen engen Bezug zum Wunsch nach Wiedererweckung des Toten aufzuweisen. ${ }^{82}$

Auf völlig andere Weise sorgten im griechischsprachigen Kleinasien sowohl Juden und Christen als auch Andersgläubige für den Schutz ihrer Gräber, nämlich gut sichtbar. ${ }^{83}$ In der Zeit vom 4. Jh. v. Chr. bis zum 4. Jh. n. Chr. beugte man mit einer Beschwörung der Götter auf Grabsteinen vor, damit niemand das Grab störe, oder ließ Verfluchungen gegen diejenigen anbringen, welche die Totenruhe behelligen sollten. ${ }^{84}$ Die

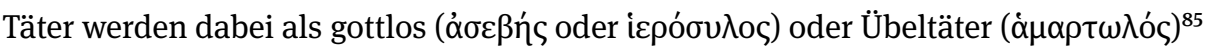
gegenüber den Göttern bezeichnet. ${ }^{86}$ Die Strafe für einen potentiellen Grabschänder wurde entweder den Göttern überlassen oder explizit genannt. ${ }^{87}$ Erbeten wurde ein grausamer oder frühzeitiger Tod des Grabschänders selbst oder seiner Angehörigen, Blindheit, unfruchtbares Land, Kinderlosigkeit oder sogar jenseitige Leiden, wenn der Grabschänder erst einmal selbst verstorben war. ${ }^{88}$ Hierbei spielte also weniger die unmittelbare Präsenz wirkmächtiger Zukunftshoffnungen, Schutzsprüche oder dergleichen in der Nähe des Toten eine Rolle als eine für alle Welt sichtbare Drohung. Ohne Flüche kommen dagegen christliche Grabsteine aus, die mit hoffnungsvollen Zitaten aus der Heiligen Schrift versehen wurden. ${ }^{89}$ Doch bereits seit dem Alten Reich konnten im antiken Ägypten Inschriften zum Schutz des Grabs mit Verfluchungen gegen die Täter erweitert werden. ${ }^{90}$

80 Donaldson 1938, 72.

81 Agius 2005, 369.

82 Agius 2005, 371. Straußeneier wurden in Ägypten und Syrien an Heiligengräbern auch als Votivgaben dargebracht; vgl. Kriss/Kriss-Heinrich 1960, 88, 120, 123, 136, 229, 238 u. Abb. Nr. 69.

83 Strubbe 1991, 33, 35.

84 Strubbe 1991, 35, 38-40; Strubbe 1997, XIV-XV. In griechischen Gebieten außerhalb Kleinasiens war diese Art des Schutzes für Gräber nicht in Gebrauch, hatte aber im Vorderen Orient eine lange Tradition. Auch sabäische Grabinschriften konnten einen schützenden Fluch beinhalten; vgl. Stein 2011, 396-398. Katalog sämtlicher Verwünschungen gegen Grabschänder auf kleinasiatischen Grabsteinen bei Strubbe 1997.

85 Zur Interpretation dieses Wortes vgl. Strubbe 1991, 34.

86 Strubbe 1991, 33f.

87 Strubbe 1991, 35.

88 Vgl. Strubbe 1997, XVII-XIX.

89 Luijendijk 2011, 405.

90 Theis 2014, 448-450, 490-519. Leisten macht darauf aufmerksam, dass islamische Mausoleen gelegentlich dazu genutzt wurden, in unsicheren Zeiten Wertgegenstände darin zu verstecken; vgl. Leisten 1998, 64. Jedoch wussten Plünderer in der Regel davon und suchten dann gerade dort. 
Auf doppelte Weise konnten Nägel wirken, die in etlichen Gräbern, besonders im westlichen Teil des Römischen Reiches, entdeckt wurden und denen eine apotropäische Funktion zugeschrieben wird. Von dieser Interpretation ausgeschlossen sind solche Nägel, die eindeutig zu einem inzwischen verrotteten Sarg oder Grabbeigaben gleichen Schicksals gehörten. Bei überdurchschnittlich großen Exemplaren, insbesondere in Aschenurnen, bis hin zur Unbrauchbarkeit verdrehten und solchen aus Glas und ähnlichem für profane Nägel ungeeignetem Material kann dies jedoch nicht der Fall gewesen sein. ${ }^{91}$ Diese Nägel, die mit Absicht in die Bestattung gelangt sein müssen, konnten gleich zwei apotropäische Zwecke erfüllen: Sie konnten sowohl den Verstorbenen vor bösen Geistern schützen als auch die noch Lebenden vor dem ruhelosen Geist des jeweiligen Verstorbenen. ${ }^{92}$ Dabei können beide Funktionen gleichzeitig erfüllt werden..$^{93}$ Identisches ist noch in jüngster Zeit in islamisch geprägten Kulturen zu beobachten, wo gelegentlich Eisen- oder Stahlstücke auf dem Körper des Verstorbenen platziert werden; in Marokko kann sogar ein Dolch oder eine Pflugschar, eine Sichel oder eine Schere den Leichnam beschweren. ${ }^{94}$

\section{$4 \mathrm{Zu}$ Lebzeiten getragene Amulette als Grabbeigaben}

Eine doppelte Funktion übernahmen in gewisser Weise auch solche Amulette, die, im Unterschied zu den oben behandelten, speziell für das Grab angefertigten, zuerst zu Lebzeiten ihres Besitzers zum Einsatz kamen, bevor sie ins Grab beigegeben wurden. Da es sich bei Amuletten um Artefakte handelte, die nach Benutzung nicht in falsche Hände geraten sollten, konnte das Beerdigen derselben mit dem Besitzer neben der physischen Zerstörung eine weitere Möglichkeit darstellen, eine Weiterverwendung zu verhindern. ${ }^{95}$ Neben entsprechenden Beobachtungen, die für die jüngere Vergangenheit vor allem von ethnologischer Forschung geliefert werden, sowie ikonographischen Indizien machen uns vor allem Originalfunde auf sie aufmerksam. Dabei fällt es in der Regel schwer zu urteilen, ob es sich um speziell angefertigte Grabamulette oder um weiterverwendete Amulette aus Lebzeiten handelt.

91 Alfayé Villa 2010, $428 f$.

92 Zum Schutz von Lebenden mit Hilfe von Gräbern s. u.

93 Auch wenn nicht klar ist, ob die Nägel mit apotropäischem Zweck für Lebende nur in Gräber von Toten gelegt wurden, die klassischerweise als ruhelos galten - wozu gewaltsam und zu früh Gestorbene zählten -, fällt auf, dass unter den Gräbern mit Nägeln auffällig häufig Kleinkindbestattungen sind; Alfayé Villa 2010, 444-450.

94 Westermarck 1926, II, 451; Schienerl 1980, 490-491, 516.

95 Kiyanrad 2017, 297-298. 
In Ägypten wurden seit prädynastischer Zeit als apotropäisch geltende Artefakte, wie diverse Anhänger, beispielsweise in Skarabäenform, oder Spiegel in Gräber beigegeben. Diesem Brauch blieb man treu, auch noch zu einer Zeit, als das Christentum bereits offizielle Religion des Imperium Romanum geworden war und sich die klassischen Amulette zusammen mit Kreuzen aus diversen Materialien in Gräbern fanden. Selbst in arabischer Zeit wurden all diese Artefakte noch beigegeben, wobei die Kreuze wie klassische Amulette auf dem Brustkorb der verstorbenen Christen platziert sein konnten. ${ }^{96}$ Ihnen wurden teilweise ganze Abschriften biblischer Bücher mit ins Grab gegeben. ${ }^{97}$ Im Falle christlicher Gräber geht Bollók davon aus, dass es ebenso wie bei paganen Bestattungen möglich war, dass sämtliche schützende Beigaben nicht nur der verstorbenen Seele nützen sollten, sondern auch den körperlichen Überresten..$^{98}$

Eine durch Funde in Gräbern häufig belegte Amulettgruppe sind lamellae. Dies sind dünne Blättchen aus Gold, Silber, Bronze oder Kupfer, in die ein apotropäischer Text eingeritzt ist und die im gesamten Imperium Romanum verbreitet waren. ${ }^{99}$ Exemplare aus Frankreich und Regensburg waren bei ihrer Entdeckung noch immer zusammengerollt in einer Amulettkapsel auf dem Brustkorb des Skeletts ihres Besitzers bzw. ihrer Besitzerin platziert. ${ }^{100}$ Allerdings wurden sie nicht mit der Intention produziert, den Toten im Jenseits zu beschützen, ${ }^{101}$ da die Texte zumeist für einen akuten Schutz im Leben formuliert waren. So sollten in Gräbern gefundene lamellae beispielsweise für Fruchtbarkeit oder Gesundheit sorgen oder Haus und Familie schützen. ${ }^{102}$ Dass von denen, deren Fundkontext bekannt ist, die meisten in Gräbern entdeckt wurden, mag damit zusammenhängen, dass Edelmetalle außerhalb von solch verborgenen Aufbewahrungsorten auf Grund ihres Wertes gerne wiederverwendet wurden, folglich vermehrt in Gräbern verborgen die Jahrhunderte überdauern konnten. Trotzdem besteht die Möglichkeit von den lamellae und ihren Fundkontexten ausgehend, zu schlussfolgern, dass potentiell auch ein großer Teil der Papyrus-

96 Beispiele für Nekropolen, an denen sich die Schutzobjekte verschiedener Traditionen gemeinsam finden lassen, in Pleşa 2017. Zu Beigaben im frühen Byzanz vgl. Bollók 2013, 227f. und zu Kreuzanhängern als Amuletten vgl. Bollók 2013, 237f. Siehe auch Korsvoll 2018, bes. 155-159.

97 Luijendijk 2011, 404.

98 Bollók 2013, 239

99 Übersicht über die Fundorte bei Kotansky 1994, xxi-xxiii.

100 Kotansky 1994, Nr. 9, 12.

$101 \mathrm{Zu}$ Ausnahmen, die genauso vor dem Tod selbst und Gefahren im Jenseits bewahren sollten, vgl. Kotansky 1994, 95f. mit weiteren Verweisen.

102 Beispiele: Fruchtbarkeit: Kotansky 1994, Nr. 61; Gesundheit: ebd., Nr. 31, 45, 53, 56, 57, 59; Schutz eines Hauses und seiner Bewohner: ebd., Nr. 41. Kotansky 1994, 220 geht sogar davon aus, dass diese lamella im Haus aufgehängt war. 
amulette, deren Herkunft in der Regel unbekannt ist, ihren verstorbenen Besitzern mit ins Grab gegeben wurde. ${ }^{103}$

Dass auch bei Erstverwendung profane Objekte als Amulette mit in Gräber gegeben wurden, zeigen einige großformatige Holztafeln des 5.-8. Jh. aus Ägypten, die mit unterschiedlichen Bibelzitaten beschrieben sind. Die Tafeln wurden ursprünglich als Schreibmaterial für Schulübungen oder andere profane Zwecke gebraucht, im Folgenden aber möglicherweise wegen ihres schutzbringenden, christlichen Inhalts zum Schutz von Gräbern weiterverwendet. ${ }^{104}$

In den klassischen islamischen Quellen sind Indizien für Grabbeigaben dagegen rar; ein einziger entsprechender Hinweis in den Hadithen mag das rote Stück Stoff (qațīfa ḥamrā') bzw. Kleid (oder Teppich) sein, das dem islamischen Propheten ins Grab beigegeben worden sein soll, wobei jedoch völlig offenbleiben muss, welche Funktion dieses besaß; ${ }^{105}$ ob die qațifa „einfach in das Grab geworfen oder ob sie unter dem Propheten ausgebreitet wurde“, ist nicht gesichert. ${ }^{106}$ Während angezweifelt wird, dass die qațifa als Amulett bzw. amulettisches Artefakt zu verstehen sei, so scheint dies jedoch in Fällen aus der Frühzeit des Islam deutlich zuzutreffen, in denen Menschen den Wunsch äußerten, dass ihnen nach ihrem Tode Dinge beigegeben werden, die sie schon zu Lebzeiten besaßen und vom Propheten geschenkt bekommen haben: etwa ein Halsband und einen Stab; möglicherweise sind auch beigegebene Korane als amulettisch $\mathrm{zu}$ verstehen. ${ }^{107}$ Auch wurden den Menschen gerne andere Besitztümer, die von verehrten religiösen Persönlichkeiten stammten, ins Grab beigegeben; zum Beispiel ein Stück Stoff oder ein Haar derselben. ${ }^{108}$ Heutzutage wird mancherorts gelegentlich auch der Gebetsteppich oder ein schon zu Lebzeiten benutzter Rosenkranz beigegeben. Schließlich lassen sich auch multifunktionale Amulette nachweisen, die gegen ein ganzes Sammelsurium von Leiden schützen sollen - von denen das Grab nur eines ist; ein solches Amulett konnte sicher gleichermaßen zu Lebzeiten als auch nach dem Tod getragen werden. ${ }^{109}$

Auch Münzen wurden ins Grab beigegeben, vornehmlich in den Mund des Toten; dieser in Iran alte Brauch wurde von den Arabern teilweise übernommen und war

103 Ausführlich dazu Willer 2015. Gemmen-Amulette verblieben dagegen wohl eher als Erbstück in Familienbesitz; Michel 2004, 232.

104 Zwei dieser sechs Tafeln stammen aus Gräbern in Qarāra. Ausführlich zu diesen Tafeln und ihren Verwendungszwecken vgl. Laura Willer, Schutz im Ewigen Leben? Zu großformatigen Holztafeln als Amulette und Grabbeigaben (in Vorbereitung).

105 Grütter 1956, 179 vermutet, dass das Stück Stoff „der Benutzung durch andere nach ihm entzogen werden“ sollte; damit würde es in eine andere Kategorie fallen (s. u.). Zu den unterschiedlichen Überlieferungen über Muhammads Totenkleid vgl. Halevi 2007, 85ff.

106 Grütter 1956, 180.

107 Grütter 1956, 180.

108 Donaldson 1938, 72.

109 Vgl. das von Schaefer 2006, 196-201 edierte Amulett, das sich im Metropolitan Museum of Art befindet (Mus.no. 1978.546.33). Das Grab wird in $\S 35$ erwähnt. 
auch schon in der griechischen Antike üblich, damit der Tote die Fahrt über den Styx bezahlen konnte. ${ }^{110}$ Auf eine andere Art gelangten Münzen in Gräber nahe des Sees Genezareth, die vornehmlich vom Ende des 5. Jh. bis zum Anfang des 8. Jh. angelegt wurden, also von byzantinischer bis in islamische Zeit hinein. Dass auch diese Münzen nicht wegen ihres materiellen oder nominellen Wertes in die Gräber gelangten, wird dadurch deutlich, dass sämtliche Exemplare durchbohrt sind, sodass sie als Kettenanhänger und somit als Amulett fungierten. ${ }^{111}$ Insbesondere Exemplare mit Darstellungen von Jesus, Heiligen oder dem Kaiser galten als besonders wirksam. ${ }^{112}$

\section{Hilfe aus dem Grab}

Die Verehrung von herausragenden religiösen Persönlichkeiten machte auch mit dem Tod nicht Halt. Obwohl das Pilgern zu Gräbern (arab. ziyāra) im Islam umstritten ist, so war und ist es doch weitverbreitet - wie schon in das 9. Jh. datierende Bücher, sogenannte ,Friedhofsführer ${ }^{6113}$ zeigen. An Gräbern von verehrten Personen (oder auch den Gräbern ihrer Reliquien), denen die Kraft, Segen (arab. baraka) zu spenden, zugeschrieben wurde, bildete sich typischerweise eine Art ,Amulettinfrastruktur' heraus. Dies bedeutet zum einen, dass dort z. B. Wünsche $\mathrm{e}^{114}$ und Gebete vorgetragen wurden; manchmal ließ man seine verschriftlichten Wünsche/Gebete oder Fetzen auch am Grab liegen oder band sie in seiner Nähe an und hoffte dergestalt auf Verwirklichung. Zudem konnten ,ausgediente' Amulette auch an Heiligengräbern als Opfergabe rituell entsorgt werden. ${ }^{115}$ Andererseits waren an solchen Gräbern auch Amulette und amulettische Artefakte erhältlich, die mit der baraka des Heiligen aufgeladen waren:

The baraka is taken as a gift from the saint and may be collected in mundane objects-such as drinking water or pieces of clothing, dust from a container adjacent to the tomb, and ashes from a fire supposedly kindled by the saint-that are taken away by the visitors. Around the shrine, devotees sell and buy such things as prayer books, sacred images, prayer beads, and candles. Some of these objects are left in the shrine, while others circulate back into the community, now with the added value of their baraka. ${ }^{116}$

110 Wellhausen 1897, 180. Kotansky 1994, 114. Siehe auch oben Anm. 41.

111 Delougaz/Haines 1960, 50-52. Zu Münzen als Amulett vgl. Fulghum 2001.

112 Bollók 2013, 236.

113 Schöller 2004, 295-314.

114 „Durchaus katholischer Praxis vergleichbar haben die einzelnen Heiligen unterschiedliche Zuständigkeiten, mal für Rückenschmerzen, mal für Unfruchtbarkeit, und aus diesen und ähnlichen Anlässen bepilgert man ihre Gräber [...]“; Sörries 2015, 43.

115 Kriss/Kriss-Heinrich 1960, 135.

116 McGregor 2016. Auch Stücke vom Sargtuch können begehrte Amulette sein, vgl. Sörries 2015, 50. 
Schon christliche Märtyrergräber hatten sich zu Orten der Verehrung entwickelt, denen man nahe sein wollte. Dies führte im Laufe der Entwicklung, zuerst im Osten des Römischen Reiches, dazu, dass die Leichen der Heiligen nicht nur umgebettet, sondern auch in Stücke zerteilt wurden, um als verehrte Reliquien an möglichst vielen Orten gleichzeitig den Gläubigen Heil zu spenden. ${ }^{117}$ Das Grab und der Leichnam eines schutzspendenden Heiligen war somit ironischerweise nicht vor Störungen sicher. Der private Besitz von Reliquien ersetzte das Tragen paganer Amulette zu Lebzeiten und später auch im Grab - nicht nur inhaltlich, sondern auch in der Praxis, indem die Reliquien in Reliquiarschnallen oder -kapseln aufbewahrt wurden, die den Verstorbenen auf die Brust gelegt wurden. ${ }^{118}$ Somit handelt es sich hierbei um Amulette, die schon zu Lebzeiten getragen wurden und nach dem Tod ins Grab mitgegeben wurden. Für ihre Träger war ihre fortwährende Präsenz bedeutend, im Gegensatz zur kurzfristigen Sichtbarkeit einer besuchten Reliquienstätte. Wer keine Körperreliquie erlangen konnte, dem war es abhängig vom Ort der Heiligenverehrung möglich Staub, Wasser oder Öl mit nach Hause zu nehmen. Teilweise ließ man selbst Öl durch ein Libationsreliquiar laufen, in dem das Öl mit den Knochen des Heiligen in Berührung kam. ${ }^{119}$

Im islamischen Kontext ist auch auf das birnenförmige, bei Kriss und Kriss-Heinrich beschriebene und abgebildete Amulett hinzuweisen, das aus Erde geformt ist, „die in Medina vom Grabe des Propheten weggenommen wird und die man zwecks besserer Haltbarkeit mit Stroh überklebt hat. Diese Erde wird dann mit heiligem Wasser vom Brunnen Zamzam gemischt und unter Umständen auch in das Blut des Opfertieres getaucht. Aus dieser Mischung wird eine kleine, strohüberklebte Birne von 3-4 cm Höhe hergestellt, welche als Amulett an einer Schnur getragen werden kann““. ${ }^{120}$ Eine ähnliche Funktion besitzen auch Stofffetzen und Rosenkränze, die am Grab mit der baraka des Heiligen aufgeladen und dann nach Hause mitgenommen z. B. Krankheiten entgegenwirken konnten. ${ }^{121}$

Möglicherweise ebenfalls als Amulette sind schiitische Gebetssiegel (pers. muhr-i namāz) zu betrachten, die aus der Erde um die Gräber berühmter Persönlichkeiten hergestellt werden, z. B. des vierten Kalifen 'Alī in Nağaf. ${ }^{122}$ Von Gebetssiegeln, die aus der Erde des Grabs von dessen Sohn Ḥusain in Kerbala bestehen, wurden

117 Kalinowski 2011, 11-15.

118 Kalinowski 2011, 19-21, 59-62.

119 Kalinowski 2011, $20 \mathrm{f}$.

120 Kriss/Kriss-Heinrich 1962, 51 (und Abb. 53, Fig. 5). Interessanterweise konnten diese Amulette nach einer Weile an Wirkmacht verlieren - und mussten dann wieder ,aufgeladen' werden, indem man sie für eine Weile wieder in der Nähe des Grabs befestigte; vgl. Kriss/Kriss-Heinrich 1960, 39. Schöller beschreibt, dass die Grabeserde von wichtigen muslimischen Persönlichkeiten schon im 14. Jh. als Heilmittel für Augenleiden eingesetzt wurde; vgl. Schöller 2004, 89-90.

121 Kriss/Kriss-Heinrich 1960, 39f. Selbst Gras, Wasser, Steine und Kehricht um das Grab werden mitgenommen und zur Heilung weiterverwendet; vgl. ebd., 48.

122 Vgl. Kriss/Kriss-Heinrich 1962, 51-52. 
sogar bereits seit früher Zeit Fälschungen verkauft, d. h. solche, die tatsächlich nicht aus dieser Erde bestanden. ${ }^{123}$ Die heute noch erhältlichen Exemplare müssen nicht mehr unbedingt aus der Erde nahe dem Grab in Kerbala bestehen - es reicht, dass sie aus Kerbala kommt (turbat-i Karbalā). ${ }^{124}$ Erde von den Gräbern berühmter Persönlichkeiten konnte auch in Amuletthüllen verwahrt getragen werden. ${ }^{125}$

Manchmal waren an Gräbern auch Personen, Grabwächter, tätig, die wohl auch Anweisungen zur Anfertigung von Amuletten gaben, wie es sich in der modernen ägyptischen Belletristik spiegelt. ${ }^{126}$ Tatsächlich ist aus dem Ägypten der 1. Hälfte des 20. Jhs. bekannt, dass zu Anlass des Todestags des schon genannten Husain ein Brot gebacken wurde, das aus der Erde des Grabs von Ahmad al-Badawī, dem Gründer eines großen Sufiordens, zubereitet, von Grabwächtern an unterschiedlichen Heiligengräbern gegen eine Spende ausgegeben und dann als „Amulett in der Tasche getragen“ wurde. ${ }^{127}$ Am Grabe Aḥmad al-Badawīs lässt sich zudem aufzeigen, dass die baraka selbst auf Tiere und von diesen wiederum auf Menschen übertragen werden kann. Dort wurde von einem Sufiorden nämlich ein Esel dazu dressiert, selbstständig zum Grab al-Badawīs zu gehen; die Anwesenden zupften ihm sodann Haare aus, die als Amulett mitgenommen wurden. ${ }^{128}$ Ein ähnliches Beispiel aus der gleichen Zeit stammt aus dem Sudan; dort gab es ein Heiligengrab, das der Fruchtbarkeit von Frauen zuträglich sein sollte; die Frauen mussten sieben Donnerstagnächte lang mit ihrem Mann am Grab verbringen und erhielten dann vom Grabwächter ein Amulett; wurde ein Kind geboren, so bekam der Grabwächter eine Spende. ${ }^{129}$

Diese Amulette, bei denen ein Grab dazu verhalf noch Lebende vor Schaden zu bewahren, stehen damit im deutlichen Kontrast zu solchen, bei denen der Verstorbene geschützt werden sollte. Denn Erstere wirkten nicht wie Letztere es üblicherweise taten - nämlich verborgen vor den Augen der Lebenden durch ihre alleinige Präsenz -, sondern waren im Alltagsleben mehr oder minder deutlich sichtbar. Denn wenn sie dies vielleicht auch nicht in aller Öffentlichkeit waren, weil sie unterm Gewand getragen oder in einem Privatraum des Hauses aufbewahrt wurden, so wurde ihr Besitzer doch regelmäßig an die Amulette erinnert, wenn sein Blick auf sie fiel oder er ihre Präsenz auf seinem Körper spürte.

Andererseits konnten Amulette aus dem Grabkontext auch für schädliche Zwecke eingesetzt werden. In der griechisch-römischen Antike konnten Gräber und die Geister der in ihnen Begrabenen auch noch genutzt werden, um die Lebenden je nach

123 Vgl. Bosworth 1976, 14.

$124 \mathrm{Zu}$ den Gebetssiegeln aus der Erde heiliger schiitischer Städte siehe ausführlich Venzlaff 1995 und 1998. Vgl. auch Kriss/Kriss-Heinrich 1960, 241.

125 Kriss/Kriss-Heinrich 1960, 336; Kriss/Kriss-Heinrich 1962, 61.

126 So im Roman von 'Awdat ar-rūḥ von Tawfik al-Hakim, besprochen bei Wielandt 1984, 247.

127 Kriss/Kriss-Heinrich 1960, 54.

128 Kriss/Kriss-Heinrich 1960, 72.

129 Kriss/Kriss-Heinrich 1960, 132. 
ihrer Ansicht zu schützen, zu unterstützen, ihnen zu ihrem Recht oder ersehnten Wunsch zu verhelfen. Defixiones, auf Bleitafeln aufgeschriebene Flüche wurden, um ihre Wirkung zu entfalten, im Boden oder Wasser deponiert. Einer der bevorzugten unterirdischen Plätze für sie waren Gräber, insbesondere von zu jung oder gewaltsam Verstorbenen. Von ihren ruhelosen Seelen erhoffte man sich Hilfe, in der Form, dass sie die gewünschte Verfluchung durchführen oder sie den Göttern präsentieren sollten. ${ }^{130}$ Auch wenn es sich bei den Flüchen um gegen andere gerichtete Schädigungen handelt, so sollten sie auf Seite des Akteurs ihm selbst doch immer zumindest zu seinem Willen verhelfen, wenn nicht sogar ihn vor (vermeintlichen) Anfeindungen schützen oder im Nachhinein zu seinem Recht verhelfen. Auf einer hethitischen Grabstele nutzt die Bestattete selbst ihr Grab, um denjenigen zu verfluchen, der ihren Nachkommen schaden wird. ${ }^{131}$

In ähnlicher Manier wurde in Marokko zu Beginn des 20. Jh., Westermarcks Beobachtungen zufolge, ein Stück eines Leichentuchs vergraben, das mit dem Namen desjenigen beschriftet war, der dem Wunsch des Auftragsgebers gemäß nicht heiraten sollte. Dieses Stück wurde dann zusammen mit einem fremden Toten bestattet. ${ }^{132}$ Auf ähnliche Weise konnte ein Artefakt hergestellt werden, das den Ehemann daran hindern sollte, seine Frau zu betrügen; das Stück Leichentuch, in das ein Zettel (vermutlich mit Koranversen) eingewickelt wurde, musste zunächst unter dem Zelteingang vergraben werden; war der Ehemann darüber geschritten, konnte seine Frau es ausgraben, in ein Ziegenhorn stecken, und dieses dann im Grab eines Unbekannten bestatten. ${ }^{133}$ Selbst Körperteile von Verstorbenen wurden als Amulette genutzt: so der kleine Finger von der rechten Hand des Toten, nämlich als Amulett für Diebe, die erhofften, mit dieser Hilfe nicht ertappt zu werden. ${ }^{134}$

\section{Fazit}

Wie anhand sämtlicher Beispiele zu sehen war, wurde in jeglichen antiken Kulturen des östlichen Mittelmeerraumes der Schutz sowohl des Grabraums als auch des in ihm ,wohnenden“ Toten für wesentlich erachtet. Wer sich nicht um seine verstorbenen Angehörigen kümmerte, dem stand auch kein eigenes Begräbnis zu, das nötig war, um ein Leben im Jenseits führen zu können. ${ }^{135}$ Dementsprechend gibt auch ein Sohn in einem Brief aus dem 3. Jh. v. Chr. an, dass es ihm das wichtigste Anliegen

130 Vgl. Gager 1992, 18-20 und Kropp 2016, 75f., 92-94.

131 Klinger 2011, 75f. Da von Ur-Ur-Ur-Enkeln die Rede ist, muss sich der Fluch auch auf die Schädigung ungeborener Nachkommen beziehen.

132 Westermarck 1926, II, 555.

133 Westermarck 1926, II, 555-556.

134 Westermarck 1926, II, 556.

135 Kreuzsaler 2013, 50-53. 
sei, seinen Vater nicht nur zu Lebzeiten, sondern auch nach dem Tod noch ehrenvoll zu beschützen. ${ }^{136}$ Dass dieses Ziel über Zeit und Raum weitverbreitet war, zeigt sich exemplarisch auch in islamisch geprägten Kulturen.

Die einzelnen Objekte bzw. Objektgruppen verdeutlichen, dass sich der Schutz des Verstorbenen sowohl auf seine körperlichen Überreste bzw. seinen ,Zwischenzustand“ im Grab bezog als auch auf das Weiterleben des Toten im Jenseits - sei es bei Osiris, im Hades oder im Paradies. Dieser Schutz war sowohl wegen weltlicher Gefahren in Form von Grabräubern nötig als auch wegen der Gefahren und Prüfungen, die den Toten im Grab oder der jenseitigen Welt erwarteten. Erlangt wurde der Schutz, wenn auch in unterschiedlichen Ausprägungen, hauptsächlich durch Amulette unterschiedlicher Form und mit differierenden Funktionen. Bestattungen bezeugen, dass Amulette nicht nur von Lebenden als Schutz im Alltag getragen wurden. Sie konnten speziell für eine Anwendung im Grab mit entsprechender Aufschrift angefertigt werden oder das Apotropaion, das der Gestorbene zu Lebzeiten immer bei sich trug, wurde ihm ins Grab beigegeben. Möglicherweise war die Kette mit schützendem Anhänger schon seit Lebzeiten an seinem Hals befestigt und verblieb einfach dort. Eine andere Möglichkeit war, dem Verstorbenen Amulette schlicht auf den Körper zu legen, zumeist auf die Brust. $\mathrm{Zu}$ seinem eigenen Schutz im Leben konnte man auch Materialien anderer Gräber nutzen, insbesondere die von Heiligengräbern. Eine explizit gegen Feindliches gerichtete Variante des Grabschutzes war, Flüche und Drohungen schriftlich auszusprechen. Andererseits hatten Vorstellungen von Tod und dem Schicksal der Verstorbenen immer schon eine Art doppelten Boden; deshalb eigneten sich mit dem Tod in Berührung gekommene Materialien auch besonders zur Herstellung von Schadensamuletten.

Amulette in Gräbern, seien sie vorher bereits zu Lebzeiten benutzt worden oder nicht, stehen insofern im Kontrast zu denen tagtäglicher Anwendung, dass sie immer am selben Ort verbleiben, an einem sehr speziellen Ort, für den sie explizit ausgewählt wurden, wenn nicht sogar erst produziert. Dort waren sie zwar für den Toten sehr präsent und wirkten je nach Inhalt auf ihn bzw. auf alles, was ihm feindlich war, konnten in der Mehrzahl der Fälle jedoch nicht mehr von den Lebenden wahrgenommen werden. ${ }^{137}$ Ausnahmen bilden nur Familiengrüfte und die ägyptischen Grabanlagen, zu denen die Priester zur Versorgung der Mumien Zugang hatten, und ggf. im Umfeld von Grabanlagen sichtbar angebrachte Amulette und Zeichnungen, seien sie primär für den Schutz des Verstorbenen oder den der Lebenden angefertigt. Im Falle eines Grabeinbruches kamen die Amulette, Symbole und Schutzsprüche den Grabschändern dergestalt zu Gesicht, auch wenn sie in diesem Moment offenbar ihre Wirkung verfehlt hatten. Die Anrufungen an übernatürliche Wesen oder eben den

136 P. Petr. II 13 (19).

137 Zur Zugänglichkeit und damit Sichtbarkeit von Psalm 90 in seiner Schutzfunktion vgl. Kraus, in diesem Band. Zur (restringierten) Sichtbarkeit von Grabbeigaben vgl. Augstein in diesem Band. 
einen Gott sollten jedoch ihre Wirkung zu jeder Zeit vollführen. Denn „im Verständnis der Ägypter können Götter auch Verborgenes lesen.“"138

\section{Literaturverzeichnis}

Agius, Dionisius Albertus (2005), ,,Leave your homeland in search of prosperity‘. The ostrich egg in a burial site at Quseir al-Qadim in the Mamlūk period“, in: Urbain Vermeulen u. Jo van Steenbergen (Hgg.), Egypt and Syria in the Fatimid, Ayyubid and Mamlūk eras. Bd. IV, Leuven, 355-379.

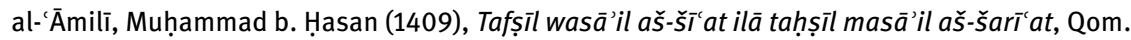
al-'Āmilī, Muhammad b. Ḥasan (1412), Hidāyat al-umma ilā aḥkām al-ā'ima, Maschhad.

Alfayé Villa, Silvia (2010), „Nails for the Dead: A Polysemic Account of an Ancient Funerary Practice“, in: Richard L. Gordon u. Francisco Marco Simón (Hgg.), Magical Practice in the Latin West. Papers from the International Conference Held at the University of Zaragoza, 30 Sept. -1 Oct. 2005, Leiden/Boston, 427-456.

Arlt, Carolin (2011), Deine Seele möge leben für immer und ewig. Die demotischen Mumienschilder im British Museum (Studia Demotica 10), Leuven.

Bagnera, Alessandra (2011), „Islamic Udegram. Activities and new perspectives“, in: Journal of Asian Civilizations 34 (1), 224-241.

Becker, Felicitas (2009), „Islamic Reform and Historical Change in the Care of the Dead: Conflicts over Funerary Practice Among Tanzanian Muslims“, in: Africa: The Journal of the International African Institute 79 (3), 416-434.

Bernabé, Alberto/Jiménez San Cristóbal, Ana Isabel (2008), Instructions for the Netherworld. The Orphic Gold Tablets (Religions in the Graeco-Roman World 162), Leiden/Boston.

Bhalla, Ajit S. (2009), Royal Tombs of India, $13^{\text {th }}$ to $18^{\text {th }}$ Century, Ahmedabad.

Bollók, Ádám (2013), „Apotropaion and Burial in Early Byzantium: Some Preliminary Considerations“, in: Erika Juhász (Hg.), Byzanz und das Abendland: Begegnungen zwischen Ost und West (Bibliotheca Byzantina 1), 227-241.

Bosworth, Clifford Edmund (1976), The Medieval Islamic Underworld: The Banū Sāsān in Arabic Society and Literature. Vol. II, Leiden.

Bunce, Frederick W. (2004), Islamic Tombs in India. The Iconography and Genesis of Their Design, New Delhi.

al-Būnī, Aḥmad b. 'Alī (1322), Šams al-ma'ārifal-kubrā, Beirut.

Capart, J./Gardiner, A. H./van de Walle, B., „New Light on the Ramesside Tomb-Robberies“, in: The Journal of Egyptian Archaeology 22 (2), 169-193.

Clark, Reg (2016), Tomb Security in Ancient Egypt from the Predynastic to the Pyramid Age (Archaeopress Egyptology 13), Oxford.

Decker, Doris (2013), Frauen als Trägerinnen religiösen Wissens. Konzeptionen von Frauenbildern in frühislamischen Überlieferungen bis zum 9. Jahrhundert, Stuttgart.

Delattre, Alain/Vanthieghem, Naïm (2015), „Un linceul copte-arabe inscrit de l'ancienne collection Michaelidès“, in: Chronique d'Égypte 90, 195-198.

Delougaz, Pinhas/Haines, Richard C. (1960), A Byzantine Church at Khirbat al-Karak (The University of Chicago Oriental Institute Publications 85), Chicago.

138 Arlt 2011, 227. 
Donaldson, Bess Allen (1938), The Wild Rue. A Study of Muhammadan Magic and Folklore in Iran, London.

Dresken-Weiland, Jutta (2010), Bild, Grab und Wort. Untersuchungen zu Jenseitsvorstellungen von Christen des 3. und 4. Jahrhunderts, Regensburg.

Eklund, Ragnar (1941), Life between death and resurrection according to Islam, Uppsala.

Faraone, Christopher A. (2010), „A Socratic Leaf Charm for Headache (Charmides 155B-157C), Orphic Gold Leaves, and the Ancient Greek Tradition of Leaf Amulets“, in: Jitse Dijkstra, Justin Kroesen u. Yme Kuiper (Hgg.), Myths, Martyrs, and Modernity. Studies in the History of Religions in Honour of Jan N. Bremmer (Numen Book Series 127), Leiden/Boston, 145-166.

Frembgen, Jürgen Wasim (2004), „The Scorpion in Muslim Folklore“, in: Asian Folklore Studies 63, 95-123.

Fulghum, Mary M. (2001), „Coins Used as Amulets in Late Antiquity“, in: Sulochana R. Asirvatham, Corinne Ondine Pache u. John Watrous (Hgg.), Between Magic and Religion. Interdisciplinary Studies in Ancient Mediterranean Religion and Society, Lanham.

Gager, John G. (1992), Curse Tablets and Binding Spells from the Ancient World, New York.

Galloway, Dalton (1922), „The Resurrection and Judgment in the Kor'an“, in: The Muslim World 12 (4), 348-372.

Gruber, Christiane (2016), „Curse Signs The Artful Rhetoric of Hell in Safavid Iran“, in: Christian Lange (Hg.), Locating Hell in Islamic Traditions, Leiden, 297-335.

Grütter, Irene (1956), „Arabische Bestattungsbräuche in frühislamischer Zeit“, in: Der Islam 32 (2), 168-194.

Halevi, Leor (2007), Muhammad's Grave. Death Rites and the Making of Islamic Society, New York.

Höveler-Müller, Michael (2007), Das Gold der Horusfalken. Auf den Spuren altägyptischer Grabräuber, Mainz.

Das Islamische Totenbuch (2002), Das Islamische Totenbuch. Jenseitsvorstellungen des Islam (Nach der Dresdner und Leipziger Handschrift. Neu herausgegeben von Helmut Werner), Bergisch Gladbach.

Jansen-Winkeln, Karl (1995), „Plünderung der Königsgräber des Neuen Reiches“, in: Zeitschrift für ägyptische Sprache und Altertumskunde 122, 62-78.

Kalinowski, Anja (2011), Frühchristliche Reliquiare. Im Kontext von Kultstrategien, Heilserwartung und sozialer Selbstdarstellung (Spätantike - Frühes Christentum - Byzanz. Kunst im ersten Jahrtausend, Reihe B 32), Wiesbaden.

Kinberg, Leah (1986), „Interaction between This World and the Afterworld in Early Islamic Tradition“, in: Oriens 29/30, 285-308.

Kiyanrad, Sarah (2017), Gesundheit und Glück für seinen Besitzer. Schrifttragende Amulette im islamzeitlichen Iran (bis 1258), Würzburg.

Klinger, Jörg (2011), „Texte der Hethiter“, in: Bernd Janowski u. Daniel Schwemer (Hgg.), Grab-, Sarg-, Bau- und Votivinschriften (Texte aus der Umwelt des Alten Testaments N.F. 6), 71-77.

Korsvoll, Nils (2018), „Official Teaching and Popular Practice. Are Church Opinions on Magic Reflected in the Surviving Amulets from the Early Middle Ages?“, in: Sarah Kiyanrad, Christoffer Theis u. Laura Willer (Hgg.), Bild und Schrift auf, magischen 'Artefakten (Materiale Textkulturen 19), Berlin/Boston, 149-163.

Kotansky, Roy (1994), Greek Magical Amulets. The Inscribed Gold, Silver, Copper, and Bronze Lamellae, Part I: Published Texts of Known Provenance (Papyrologica Coloniensia XXII/1), Opladen.

Kreuzsaler, Claudia (2013), „Tote ohne Begräbnis - Die Klage der Artemisia“, in: Angelika Zdiarsky (Hg.), Wege zur Unsterblichkeit. Altägyptischer Totenkult und Jenseitsglaube (Nilus 20), Wien.

Kriss, Rudolf/Kriss-Heinrich, Hubert (1960), Volksglaube im Bereich des Islam. Band I: Wallfahrtswesen und Heiligenverehrung, Wiesbaden. 
Kriss, Rudolf/Kriss-Heinrich, Hubert (1962), Volksglaube im Bereich des Islam. Band II: Amulette, Zauberformeln und Beschwörungen, Wiesbaden.

Kropp, Amina (2016), „,... Dann trag das Bleitäfelchen weg ans Grab eines vorzeitig Verstorbenen‘ Antike Fluchtafeln als Textträger und Ritualobjekte“, in: Annette Kehnel u. Diamantís Panagiotópoulos (Hgg.), Schriftträger - Textträger. Zur materialen Präsenz des Geschriebenen in frühen Gesellschaften (Materiale Textkulturen 6), Berlin/Boston/München, 73-102.

Lange, Christian (2011), „Barzakh“, in: Encyclopaedia of Islam³, hgg. von Kate Fleet, Gudrun Krämer, Denis Matringe, John Nawas, Everett Rowson (http://dx.doi.org.ubproxy.ub.uni-heidelberg. de/10.1163/1573-3912_ei3_COM_23704, Stand 21.04.2017).

Leisten, Thomas (1998), Architektur für Tote. Bestattung in architektonischem Kontext in den Kernländern der islamischen Welt zwischen 3./9. und 6./12. Jahrhundert, Berlin.

Luijendijk, AnneMarie (2011), „Jesus says: ,There Is Nothing Buried That Will Not Be Raised'. A Late-Antique Shroud with Gospel of Thomas Logion 5 in Context“, in: Zeitschrift für antikes Christentum 15, 389-410.

Mağlisī, Muḥammad Bāqir (1412), Bīst va panğ risāla-yi fārsī, hgg. von Mehdī Rejā'̄i, Qom.

Mağlisī, Muḥammad Bāqir (1423), Biḥār al-anvār, Teheran.

Mannsbart, Agnes (2003), „Der Totenglaube der Ägypter“, in: Harald Froschauer, Christian Gastgeber u. Hermann Harrauer (Hgg.), Tod am Nil. Tod und Totenkult im antiken Ägypten (Nilus 8), Wien, 1-12.

Marshall, Frederick H. (1911), Catalogue of the Jewellery, Greek, Etruscan, and Roman in the Departments of Antiquities British Museum, London.

McGregor, Richard J. (2016), „Grave visitation/worship“, in: Kate Fleet, Gudrun Krämer, Denis Matringe, John Nawas, Everett Rowson (Hgg.), Encyclopaedia of Islam ${ }^{3}$ (http://dx.doi.org. ubproxy.ub.uni-heidelberg.de/10.1163/1573-3912_ei3_COM_27519, 2016, Stand 21.04.2017).

Meier, Fritz (1973), „Ein Profetenwort gegen die Totenbeweinung“, in: Der Islam 50 (2), 207-229.

Meurer, Georg (2002), Die Feinde des Königs in den Pyramidentexten (Orbis Biblicus et Orientalis 189), Freiburg, Schweiz/Göttingen.

Michel, Simone (2004), Die magischen Gemmen. Zu Bildern und Zauberformeln auf geschnittenen Steinen der Antike und Neuzeit (Studien aus dem Warburg-Haus 7), Berlin.

Peet, T. Eric (1930), The Great Tomb-Robberies of the Twentieth Egyptian Dynasty, Oxford.

Pleşa, Alexandra D. (2017), „Religious Belief in Burial: Funerary Dress and Practice at the Late Antique and Early Islamic Cemeteries at Matmar and Mostagedda, Egypt (Late Fourth-Early Ninth Centuries (E)“, in: Ars Orientalis 47, 18-42.

Porter, Venetia (2011), Arabic and Persian Seals and Amulets in the British Museum, London. Preisendanz, Karl (1932), „Mumienamulett auf Papyrus“, in: Études de Papyrologie 1, 19-22.

Preisendanz, Karl (1974), Papyri Graecae Magicae. Die griechischen Zauberpapyri. Bd. 2 (2. Aufl.), hg. von Albert Henrichs, Stuttgart.

Quaegebeur, Jan (1978), „Mummy Labels: an Orientation“, in: E. Boswinkel u. P. W. Pestman, Textes grecs, démotiques et bilingues (P. L. Bat. 19) (Papyrologica Lugduno-Batava 19), Leiden, 232-259.

Rahim, Mohamed (2010), „Arabische Grabinschriften aus dem Nahen Osten“, in: Jürgen Wasim Frembgen (Hg.), Die Aura des Alif. Schriftkunst im Islam, München/Berlin/London/New York, 149-159.

Rebstock, Ulrich (2002), „Das ,Grabesleben‘. Eine islamische Konstruktion zwischen Himmel und Hölle“, in: Rainer Brunner (Hg.), Islamstudien ohne Ende: Festschrift für Werner Ende zum 65. Geburtstag, Würzburg, 371-382.

Roy, Bernard/Poinssot, Paule (1950), Inscriptions arabes de Kairouan, Paris.

Schaefer, Karl R. (2006), Enigmatic Charms. Medieval Arabic Block Printed Amulets in American and European Libraries and Museums, Leiden/Boston. 
Schienerl, Peter W. (1980), „Eisen als Kampfmittel gegen Dämonen. Manifestationen des Glaubens an seine magische Kraft im islamischen Amulettwesen“, in: Anthropos 75 (3-4), 486-522.

Schöller, Marco (2004), The Living and the Dead in Islam. Studies in Arabic Epitaphs II: Epitaphs in Context, Wiesbaden.

Seligmann, Siegfried (1914), „Das Siebenschläfer-Amulett. (Mit einem Beitrage von Erich Graefe.) Mit 7 Abbildungen“, in: Der Islam 5 (4), 370-388.

O'Shaughnessy, Thomas (1969), Muhammad's Thought on Death. A Thematic Study of the Qur'anic Data, Leiden.

Smith, Jane Idleman/Haddad, Yvonne Yazbeck (1981), The Islamic Understanding of Death and Resurrection, New York.

Sörries, Reiner (2015), Von Mekka nach Berlin. Archäologie und Kulturgeschichte des islamischen Friedhofs, Wiesbaden.

Stauffer, Annemarie (1996), Spätantike, frühchristliche und islamische Textilien aus Ägypten, Bern. Stein, Peter (2011), „Altsüdarabische Grabinschriften“, in: Bernd Janowski u. Daniel Schwemer (Hgg.), Grab-, Sarg-, Bau- und Votivinschriften (Texte aus der Umwelt des Alten Testaments N.F. 6), 387-402.

Strubbe, Johan H. M. (1991), „,Cursed be he that moves my bones““, in: Christopher A. Faraone u. Dirk Obbink (Hgg.), Magika Hiera. Ancient Greek Magic and Religion, New York/Oxford, 33-59.

Strubbe, Johan H. M. (Hg.) (1997), APAI EПITYMBIOI. Imprecations Against Desecrators of the Grave in the Greek Epitaphs of Asia Minor. A Catalogue (Inschriften griechischer Städte aus Kleinasien 52), Bonn.

Tesei, Tommaso (2016), „The barzakh and the Intermediate State of the Dead in the Quran“, in: Christian Lange (Hg.), Locating Hell in Islamic Traditions, Leiden, 31-55.

Theis, Christoffer (2011), Deine Seele zum Himmel, dein Leichnam zur Erde. Zur idealtypischen Rekonstruktion eines altägyptischen Bestattungsrituals (Studien zur Altägyptischen Kultur, Beihefte 12), Hamburg.

Theis, Christoffer (2014), Magie und Raum. Der magische Schutz ausgewählter Räume im alten Ägypten nebst einem Vergleich zu angrenzenden Kulturbereichen (Orientalische Religionen in der Antike 13), Tübingen.

Torallas Tovar, Sofía (2013), „Egyptian Burial Practices in Late Antiquity: the Case of Christian Mummy Labels “, in: Sofía Torallas Tovar u. Juan Pedro Monferrer-Sala (Hgg.), Cultures in Contact. Transfer of Knowledge in the Mediterranean Context (Syro-Arabica 1), Córdoba, 13-24.

Venzlaff, Helga (1995), „Mohr-e Namāz: Das schiitische Gebetssiegel“, in: Die Welt des Islams 35 (2), 250-275.

Venzlaff, Helga (1998), „Gebetssiegel und Gebetstuch aus Qum“, in: Die Welt des Islams 39 (2), 218-230.

Vleeming, Sven P. (2011), Demotic and Greek-Demotic Mummy Labels. And Other Short Texts Gathered from Many Publications (Studia Demotica 9), Leuven.

Wellhausen, Julius (1879), Reste arabischen Heidentums, Berlin.

Westermarck, Edward (1926), Ritual and Belief in Morocco. 2 Vols., London.

Wielandt, Rotraut (1984), „Die Bewertung islamischen Volksglaubens in ägyptischer Erzählliteratur des 20. Jahrhunderts“, in: Die Welt des Islams XXIII-XXIV, 244-258.

Willer, Laura (2015), „Beschreib es und trag es versteckt. “ Sogenannt magische Papyrusamulette aus dem römischen Ägypten in der Praxis - Ihre Herstellung und Handhabung (Diss. Heidelberg). 